\title{
The Role of OsWRKY Genes in Rice When Faced with Single and Multiple Abiotic Stresses
}

\author{
Rajendran Jeyasri ${ }^{1}$, Pandiyan Muthuramalingam ${ }^{1,2}{ }^{(\mathbb{D}}$, Lakkakula Satish ${ }^{1,3} \mathbb{D}^{\circ}$, Sivakumar Adarshan ${ }^{1}$, \\ Muthukannan Aishwarya Lakshmi ${ }^{1}$, Shunmugiah Karutha Pandian ${ }^{1} \mathbb{D}^{\mathbb{D}}$, Jen-Tsung Chen ${ }^{4}{ }^{\mathbb{D}}$, Sunny Ahmar ${ }^{5, *}$, \\ Xiukang Wang ${ }^{6}\left(\mathbb{D}\right.$, Freddy Mora-Poblete ${ }^{5} \mathbb{D}$ and Manikandan Ramesh ${ }^{1, *(1)}$
}

1 Department of Biotechnology, Science Campus, Alagappa University, Karaikudi 630003, Tamil Nadu, India; jeyasri8220@gmail.com (R.J.); pandianmuthuramalingam@gmail.com (P.M.); lsatish@post.bgu.ac.il (L.S.); sadarshan1999@gmail.com (S.A.); aishwaryakannan08@gmail.com (M.A.L.); pandiansk@gmail.com (S.K.P.)

2 Department of Biotechnology, Sri Shakthi Institute of Engineering and Technology, Coimbatore 641062, Tamil Nadu, India

3 Department of Biotechnology Engineering, Ben-Gurion University of the Negev, Beer Sheva 84105, Israel

4 Department of Life Sciences, National University of Kaohsiung, Kaohsiung 811, Taiwan; jentsung@nuk.edu.tw

5 Institute of Biological Sciences, University of Talca, 2 Norte 685, Talca 3460000, Chile; morapoblete@gmail.com

6 College of Life Sciences, Yan'an University, Yan'an 716000, China; wangxiukang@yau.edu.cn

* Correspondence: sunnyahmar13@gmail.com (S.A.); mrbiotech.alu@gmail.com (M.R.)

Citation: Jeyasri, R.;

Muthuramalingam, P.; Satish, L.; Adarshan, S.; Lakshmi, M.A.;

Pandian, S.K.; Chen, J.-T.; Ahmar, S.; Wang, X.; Mora-Poblete, F.; et al. The Role of OsWRKY Genes in Rice When Faced with Single and Multiple Abiotic Stresses. Agronomy 2021, 11, 1301. https://doi.org/10.3390/ agronomy11071301

Academic Editors: Kwon-Kyoo Kang and Yong-Gu Cho

Received: 9 June 2021

Accepted: 24 June 2021

Published: 26 June 2021

Publisher's Note: MDPI stays neutral with regard to jurisdictional claims in published maps and institutional affiliations.

Copyright: (c) 2021 by the authors. Licensee MDPI, Basel, Switzerland. This article is an open access article distributed under the terms and conditions of the Creative Commons Attribution (CC BY) license (https:// creativecommons.org/licenses/by/ $4.0 /)$.

\begin{abstract}
The WRKY genes are one of the largest families of transcription factors (TFs) and play a crucial role in certain processes in plants including stress signaling, regulation of transcriptional reprogramming associated with stress responses, and other regulatory networks. This study aims to investigate the WRKY gene family in the $C_{3}$ model plant, Oryza sativa L., using a genome-wide in silico expression analysis. Firstly, 104 WRKY TF family members were identified, and then their molecular properties and expression signatures were analyzed systematically. In silico spatio-temporal and hormonal expression profiling revealed the roles of OsWRKY genes and their dynamism in diverse developmental tissues and hormones, respectively. Comparative mapping between OsWRKY genes and their synteny with $C_{4}$ panicoid genomes showed the evolutionary insights of the WRKY TF family. Interactions of OsWRKY coding gene sequences represented the complexity of abiotic stress (AbS) and their molecular cross-talks. The expression signature of 26 novel candidate genes in response to stresses exhibited the putative involvement of individual and combined AbS (CAbS) responses. These novel findings unravel the in-depth insights into OsWRKY TF genes and delineate the plant developmental metabolisms and their functional regulations in individual and CAbS conditions.
\end{abstract}

Keywords: abiotic stress; comparative mapping; GWAS; Oryza sativa; OsWRKY; transcription factor

\section{Introduction}

As sessile organisms, plants are continuously exposed to adverse environmental conditions which may cause deleterious impacts on their growth, development, and productivity. Abiotic stresses (AbS) are predominant among various environmental stresses, which include drought, low temperature or cold stress, salinity, submergence, heavy metal, and other forms of oxidative stress such as radiation. At present, global agriculture is facing a serious threat from climatic changes, which is another aggravating challenge that affects the sustainability and productivity of crop plants [1]. Plants have well-developed defense responses to ensure survival under these environmental stresses and exhibit stress avoidance/stress tolerance through acclimation and adaptation mechanisms [2]. On deeper insight of stress, initiation of complex abscisic acid (ABA) -dependent and/or -independent signal transduction pathways and its manifestation at physiological, molecular, and metabolic responses that ultimately elevate the stress tolerance in plants [3]. 
Transcription factors (TFs) are the pivotal players involved in the stress signaling pathways, transcriptional reprogramming, cell division, plant growth, development, and stimulating the abiotic stress-responsive (AbSR) genes [4,5]. The TFs may afford signaling cascades or gene networks, in which they regulate other TFs and/or functional regulatory elements through their specific binding sequences [6,7]. The plant genome devotes approximately $7 \%$ putative TFs [8] that are classified into 58 TF families [9]. Among these, WRKY is the seventh-largest family of TFs (https: / /grassius.org/, accessed on 4 December 2020) that are mainly found in higher plants with 74 members in Arabidopsis and up to 104 members predicted in Oryza sativa [10]. WRKY TF domain is composed of a conserved WRKYGQK sequence motif and a CX5-8CX25-28HX1-2C or CX4-5CX22-23HXH (metal-chelating zinc finger) motif [11]. WRKY TFs contain 60 highly conserved amino acids with a WRKY motif sequence at its amino-terminal end and a putative zinc finger domain at its carboxyterminal end [12]. The WRKY family could specifically bind on the W-box promoter region with consensus sequence $(\mathrm{C} / \mathrm{T}) \mathrm{TGAC}[\mathrm{T} / \mathrm{C}]$, which targets the downstream genes and stimulates their expression dynamism. In addition, WRKY TFs can bind to both W-box and a sugar-responsive (SURE) cis-element (TAAAGATTACTAATAGGAA) and activate the transcription machinery of downstream genes [13].

To the best of our knowledge, WRKY TFs are involved in functional regulation of diverse physiological and molecular processes including pollen development and its function [14], seed dormancy [15], trichome development [16], seed development [13,16,17], flowering time and plant height [18], somatic embryogenesis [19,20], biomass [21,22], secondary metabolite biosynthesis [13,23-25], hormone signaling [26] and leaf senescence [27-29]. Most importantly, WRKY TFs have been shown to get activated in response to different biotic $[10,30]$ and AbS [31,32], including pathogen infection [33,34], oxidative stress [35], drought, cold, high salinity [36], wounding [37], freezing [38], bacterial infection [39-41], viral attack [39,42], fungal invasion $[39,43,44]$, defense against oomycetes [45,46], carbohydrate anabolism, and secondary metabolism [13]. Furthermore, AbS induces the activity of various WRKY proteins, which function in synchronization to confer resistance against certain stress or provide a combinatorial effect on combined stress resistance. Some of the WRKY TFs can be differentially expressed, regulating the expression of related genes and promoting signal transduction machinery. In wheat, out of the 15 WRKY genes, 8 genes were transcribed in response to $\mathrm{NaCl}$, heat, polyethylene glycol (PEG), and cold [47]. In rice, the majority of the WRKY genes show variable responses towards PEG, salinity, cold, and heat stresses [48]. Elevated expression of 18 WRKY genes in the roots of $\mathrm{NaCl}$ treated Arabidopsis plants were confirmed via microarray profiling [49]. The expression profiling and functional identifications of WRKY TFs in most studies are generally based on genetic transformation, real-time fluorescence quantitative PCR, and transcriptome analyses. Hence, WRKY genes can function effectively in different abiotic stress responses or tolerances in rice and various crop plants.

The potential role of WRKY TF family members in various molecular, physiological and biological processes has been studied extensively in a variety of crop plants [50-54]. However, a systematic view of WRKY TFs in the C3 model plant, O. sativa (OsWRKY) is still inadequate. In view of its importance, high-throughput in silico approaches have been used to identify the potential AbSR-OsWRKY TF family members for the first time. This study provides the functional aspects of these AbSR-OsWRKY TFs and spotlights potential candidates for further characterization toward representing their functional role in AbS dynamism.

\section{Materials and Methods}

\subsection{In Silico Mining and Meta-Analysis of WRKY TF Genes in O. sativa}

The WRKY family members and their encoding gene sequences of $O$. sativa were retrieved from the GRASSIUS Grass Regulatory Information Server (http:/ / grassius.org/g rasstfdb.html, accessed on 4 December 2020) [55]. OsWRKY TF family members and their RAP ID/locus ID were collected and used for further analyses. Furthermore, WRKY genes 
with their IDs were used to fetch the corresponding genomic, transcriptomic, and coding sequences along with their chromosomal positions were collected from the RGAP (Rice Genome Annotation Project Database) (http:/ / rice.plantbiology.msu.edu/, accessed on 24 December 2020) [56].

\subsection{Spatio-Temporal and Phytohormone Expression Analysis}

OsWRKY genes were exported to the spatio-temporal (RXP_0001) dataset and plant hormone (RXP_1001 RXP_1012) dataset of rice expression profile database (RiceXPro) (http://ricexpro.dna.affrc.go.jp/, accessed on 16 January 2020) [57] for analyzing the spatio-temporal gene expression profile covering different tissues/organs and cell types at various developmental stages, and plant hormone responses, respectively using publicly available microarray.

\subsection{Gene Features and Phylogenetic Analysis}

Gene properties including amino acid length, molecular weight (M.Wt), isoelectric point (pI), instability index, aliphatic index, and grand average hydropathicity (GRAVY) were predicted using the online ExPASy proteomics server (http:/ / web.expasy.org/pro tparam/, accessed on 2 February 2020) [58]. The OsWRKY TF family members and their respective amino acid sequences in other $\mathrm{C}_{4}$ panicoid sequenced grass species such as foxtail millet (Setaria italica), sorghum (Sorghum bicolor), and maize (Zea mays) were also identified by BLASTP (https:/ / blast.ncbi.nlm.nih.gov / Blast.cgi?PAGE=Genes, accessed on 8 February 2020) analysis. The accession numbers of newly predicted WRKY TFs family members from $\mathrm{C}_{4}$ grass species were assigned as SiWRKY (S. italica), SbWRKY (S. bicolor), ZmWRKY (Z. mays) TF family members and their identity score values were tabulated (Supplementary Table S1). The predicted WRKY TF gene sequences confirmed the presence of WRKY DNA - binding domain and hAT family C-terminal dimerization domain by HMMSCAN (Supplementary Table S2). The amino acid sequences of OsWRKY along with SiWRKY, SbWRKY, ZmWRKY were imported into MEGA v7.0 (Philadelphia, PA, USA) [59] and multiple sequence alignment was performed using ClustalW. The parameters used in the alignment were as follows: gap opening: 10.00, and gap extension: 0.10 . The alignment file was imported to construct a phylogenetic tree by the maximum-likelihood method and bootstrap analysis was performed with 1000 replicates.

\subsection{Gene Structure Analysis and Gene Ontology Annotation}

Understanding the gene organization will aid to reveal the function, regulation, and evolution of genes. Arrangements of exons and introns were predicted by comparing the coding sequences with their genomic sequences using Gene Structure Display Server (GSDS) v2.0, a web-based bioinformatics tool (http:/ / gsds.cbi.pku.edu.cn/, accessed on 16 February 2021) [60]. Potential candidate genes and their corresponding RAP IDs were subjected to the ShinyGO v0.61 database (http:/ / bioinformatics.sdstate.edu/go/, accessed on 7 March 2021) to obtain gene ontology (GO) annotation against $O$. sativa subsp. japonica. GO enrichment was calculated by the $p$-value cut-off (FDR) at 0.01 for the genes.

\subsection{Molecular Interactome and Enrichment Analysis}

Protein-Protein Interaction (PPI) analysis was performed using STRING v11.0 (https: //string-db.org/, accessed on 20 March 2021) [61] with a high confidence score of 0.7. The functional enrichment analysis of the interactome was done through the level of 0.01 . Active interaction based on the various sources, including text mining, experiments, gene fusion, databases, and co-expression, and an interaction score $>0.4$ were applied to construct the PPI network. This interactome map was used to identify the physical and functional role of the key candidate genes involved. 


\subsection{Gene Synteny Analysis}

In order to unravel the genomic distribution of WRKY TFs, comparative mapping/gene synteny analysis was performed. OsWRKY and their orthologous genes in C4 grasses such as S. italica, S. bicolor, and Z. mays were identified by Gramene-BLASTP (reciprocal) analysis of the gene sequences against these panicoid genomes. All orthologous gene sequences and all hits with E-value $1 \mathrm{e}-0\left(1 \times 10^{0}\right)$ and minimum $60 \%$ similarity were treated as significant. The chromosomal synteny between $O$. sativa and these $\mathrm{C} 4$ grass species was then visualized by Circos v0.55 (Switzerland) [62].

\section{Results}

\subsection{Identification of the WRKY Family Transcription Factors in Rice Genome}

The GRASSIUS Grass Regulatory Information Server identified a total of 104 OsWRKY TF family members (Supplementary Table S3). These 104 genes were subjected to RiceXPro for meta-expression analysis (Supplementary Figure S1). Based on the heatmap profiling, 26 OsWRKY TF novel candidate genes were identified and these players are significantly involved in individual and CAbS responses (Table 1). Notably, these genes were localized in all the rice chromosomes except the 10th chromosome, which revealed these players divergence of chromosomes in the rice genome.

Table 1. OsWRKY TF family members and their attributes.

\begin{tabular}{ccccccc}
\hline S. NO & Gene Name & RAP ID & Start & End & Chr. No & UniProt ID \\
\hline 1 & OsWRKY1 & Os01g0246700 & 4356383 & 4340849 & 1 & Q0JQ43 \\
2 & OsWRKY6 & Os03g0798500 & 22731943 & 22733240 & 3 & Q94D50 \\
3 & OsWRKY10 & Os01g0186000 & 26688416 & 26687377 & 1 & Q0JKQ9 \\
4 & OsWRKY11 & Os01g0626400 & 25009453 & 25012236 & 1 & Q9FE35 \\
5 & OsWRKY12 & Os01g0624700 & 29723065 & 29720923 & 1 & Q5JLU2 \\
6 & OsWRKY14 & Os01g0730700 & 30604295 & 30608077 & 1 & Q942D2 \\
7 & OsWRKY23 & Os01g0734000 & 36194611 & 36193840 & 1 & Q6IEM5 \\
8 & OsWRKY24 & Os01g0826400 & 42946753 & 42948750 & 1 & Q5JM93 \\
9 & OsWRKY28 & Os06g0649000 & 26283914 & 26280253 & 6 & Q0DZ26 \\
10 & OsWRKY29 & Os07g0111400 & 28726783 & 28730933 & 7 & Q6Z8E9 \\
11 & OsWRKY32 & Os02g0770500 & 12394669 & 12396898 & 2 & Q10LT9 \\
12 & OsWRKY37 & Os04g0597300 & 31326926 & 31323190 & 4 & Q9AUV7 \\
13 & OsWRKY45 & Os05g0322900 & 30132491 & 30136547 & 5 & Q0JAI8 \\
14 & OsWRKY49 & Os05g0565900 & 4999626 & 4998210 & 5 & Q65WY5 \\
15 & OsWRKY55 & Os03g0321700 & 23530499 & 23529423 & 3 & Q6IEN3 \\
16 & OsWRKY66 & Os02g0698800 & 2958991 & 2963006 & 2 & Q5VMX9 \\
17 & OsWRKY71 & Os07g0583700 & 23659625 & 23654076 & 7 & Q84ZS7 \\
18 & OsWRKY73 & Os07g0680400 & 28832398 & 28828793 & 7 & Q7XHX5 \\
19 & OsWRKY74 & Os08g0198000 & 5669406 & 5663578 & 8 & Q0J7F5 \\
20 & OsWRKY79 & Os08g0386200 & 18220041 & 18222408 & 8 & Q6ZA22 \\
21 & OsWRKY82 & Os09g0334500 & 10128825 & 10131136 & 9 & Q6ERI5 \\
22 & OsWRKY83 & Os09g0417600 & 14977713 & 14975932 & 9 & Q6EPZ2 \\
23 & OsWRKY85 & Os09g0481700 & 18501264 & 18496949 & 9 & Q0J0V4 \\
24 & OsWRKY92 & Os11g0117500 & 789030 & 787542 & 11 & Q2RBB8 \\
25 & OsWRKY94 & Os11g0490900 & 17352085 & 17355820 & 11 & Q2R432 \\
26 & OsWRKY101 & Os12g0116700 & 825793 & 824302 & 12 & Q2QYJ6 \\
\hline
\end{tabular}

\subsection{Spatio-Temporal Expression Analysis of OsWRKY}

To detect dynamic changes in spatio-temporal expression level of 104 OsWRKY TF genes in 48 different tissue/organ, specific meta-profiling was performed and observed at diverse developmental stages of rice plants under natural field conditions (Supplementary Figure S1). Among the 104 WRKY TF genes, 26 key players (listed in Table 1) showed higher expression pattern in diverse tissues and organs such as leaf sheath (vegetative-12:00; 00:00; reproductive - 12:00; 00:00), leaf blade (vegetative-12:00; 00:00, reproductive-12:00; 00:00, ripening - 12:00; 00:00), root (vegetative $-12: 00 ; 00: 00$, reproductive-12:00; 00:00), 
inflorescence $(0.6-1.0,3.0-4.0,5.0-10 \mathrm{~mm})$, stem (ripening-12:00; 00:00), ovary (01, 03 days after flowering (DAF)), and endosperms $(07,10,14,28$ and 42 DAF (Figure 1). OsWRKY showed lower expression in stem (reproductive-12:00; 00:00), lemma (1.5-2.0, 4.0-5.0, $7.0 \mathrm{~mm}$ floret), palea (1.5-2.0, 4.0-5.0, $7.0 \mathrm{~mm}$ floret), anther (0.3-0.6, 0.7-1.0, 1.2-1.5, 1.6-2.0 mm), ovary (05 $07 \mathrm{DAF})$, and embryo (07, 10, 14, 28 and $42 \mathrm{DAF})$ (Figure 1) as imputed by RiceXPro, based on the available OsWRKY TF family members field RNASeq data.
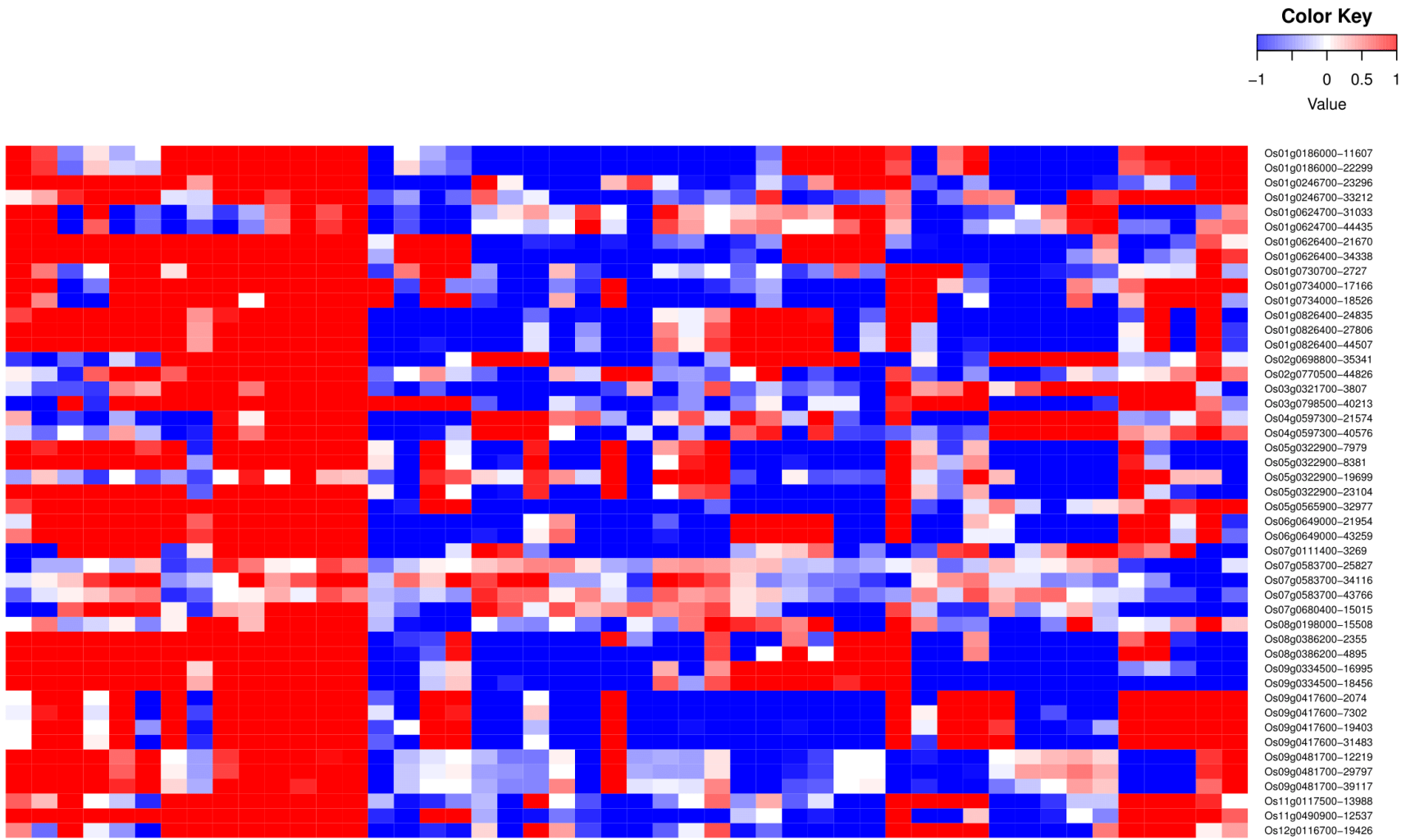

Os0190186000-11607 Oso190186000-22299 Oso1902467700-23296
Os $0190246700-33212$ Os0190624700-31033

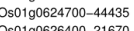
Os0190626400-21670
Os0190626400-34338 Os0190626400-34333
Oso1 $190730700-2727$ S0190734000-17166 Oso190734000-18526 0 os $190826400-27806$ os0190826400-44507 0 s0200698800-35341 $050220770500-44826$ Os03907989500-40213 S0490597300-40576 O50590322900-7979 Oso5go3222900-1969 Oso5go322900-23104 Os0590565900-32977 Oso6g0649000-21954
Os $0690649900-43259$ Os0790111400-3269

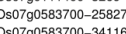
Os0790583700-34116 Os0790680400- 15015 O50890198000-15508

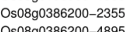
Os08g03866200-4895
Os09g0334500-16995 Os $09900417600-2074$ s0990417600-7302 So990417600-19403 Os0990481700-12219

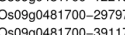
Oso9g0481700-3911 Osi1904909000-12537

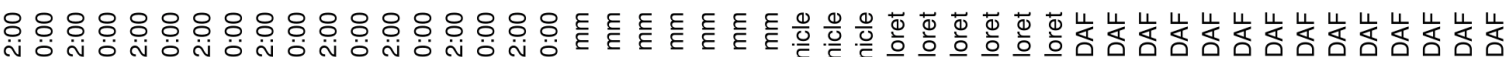
ஸ́,

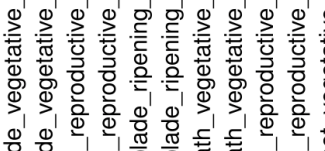

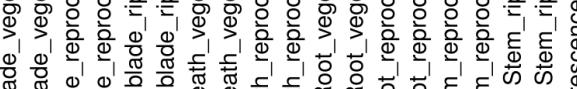

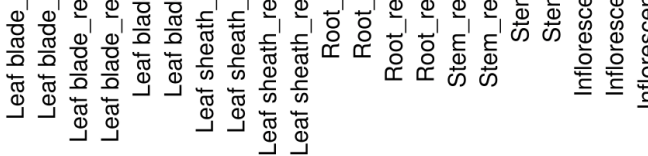
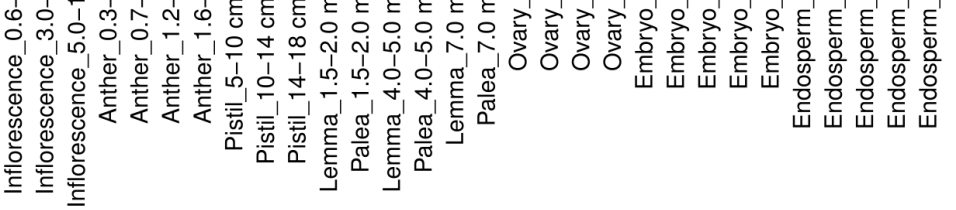

Figure 1. Heatmap of 26 potential OsWRKY TF family members showing the spatio-temporal gene expression profile of tissue/organ types at different developmental stages which are differentially expressed under natural field conditions. The red color indicates up-regulation, the blue color indicates down-regulation, and the white color indicates no expression. The color bar at the right side top represents the level of expression value, where -1 and 1 represent the down- and up-regulation of AbS responsible OsWRKY TF family members.

\subsection{Phytohormone Expression Profiling}

Twenty-six OsWRKY TF genes showed phytohormonal expression profiling in various time points such as $15 \mathrm{~min}, 30 \mathrm{~min}, 1 \mathrm{~h}, 3 \mathrm{~h}, 6 \mathrm{~h}$, and $1 \mathrm{~h}, 3 \mathrm{~h}, 6 \mathrm{~h}, 12 \mathrm{~h}$ in root and shoot, respectively. In the shoot, auxin and jasmonic acid (JA) showed high-level expression, and a negligible level of expression was observed in abscisic acid (ABA), cytokinin (CK), gibberellins (GA), and brassinosteroid (BRs) (Figure 2) at various time points. In the root, all these 26 genes were found to show higher expression in auxin, CK, and JA and lower expression in ABA, GA, BRs hormone expression levels across all the time points (Figure 3). 


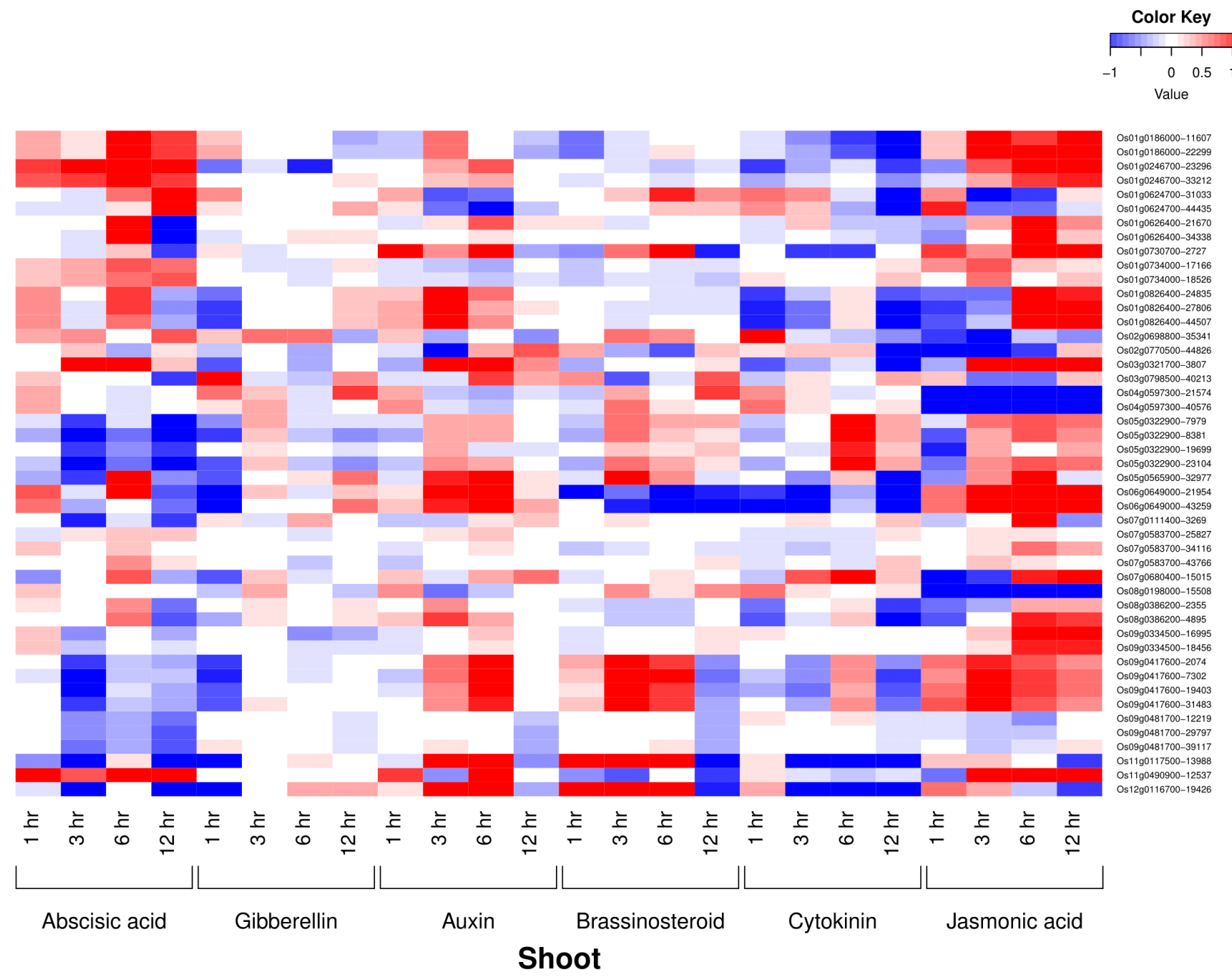

Figure 2. Heatmap representing the potential 26 AbSR-OsWRKY TF family members and their phytohormonal expression pattern in the shoot which are differentially regulated across the entire growth in the field conditions. The red color indicates up-regulation, the blue color indicates down-regulation, and the white color indicates no expression. The color bar at the right side top represents the level of expression value, where -1 and 1 represent the down- and up-regulation of AbS responsible OsWRKY TF family members.

\subsection{OsWRKY TF Genes with Their Properties}

The candidate genes and their properties such as amino acid length, M. Wt, pI, aliphatic index, instability index, GRAVY, and subcellular localization of the OsWRKY were analyzed and are given in Table 2. Among the 26 OsWRKY genes, OsWRKY28 was the smallest gene with 190 amino acids whereas OsWRKY74 was the largest one with 862 amino acids. The $\mathrm{pI}$ ranged from 9.48 (OsWRKY23) to 10.06 (OsWRKY1) and the molecular weight of the genes also varied according to gene size ranging from $20.49 \mathrm{kDa}$ (OsWRKY28) to $97.37 \mathrm{kDa}$ (OsWRKY74) (Table 2). The variation in the physiochemical properties of genes deciphered the presence of putative novel variants. Notably, many of the players were localized in the nucleus and it revealed that these OsWRKY TFs were involved in gene transcriptional and several biosynthesis processes. 

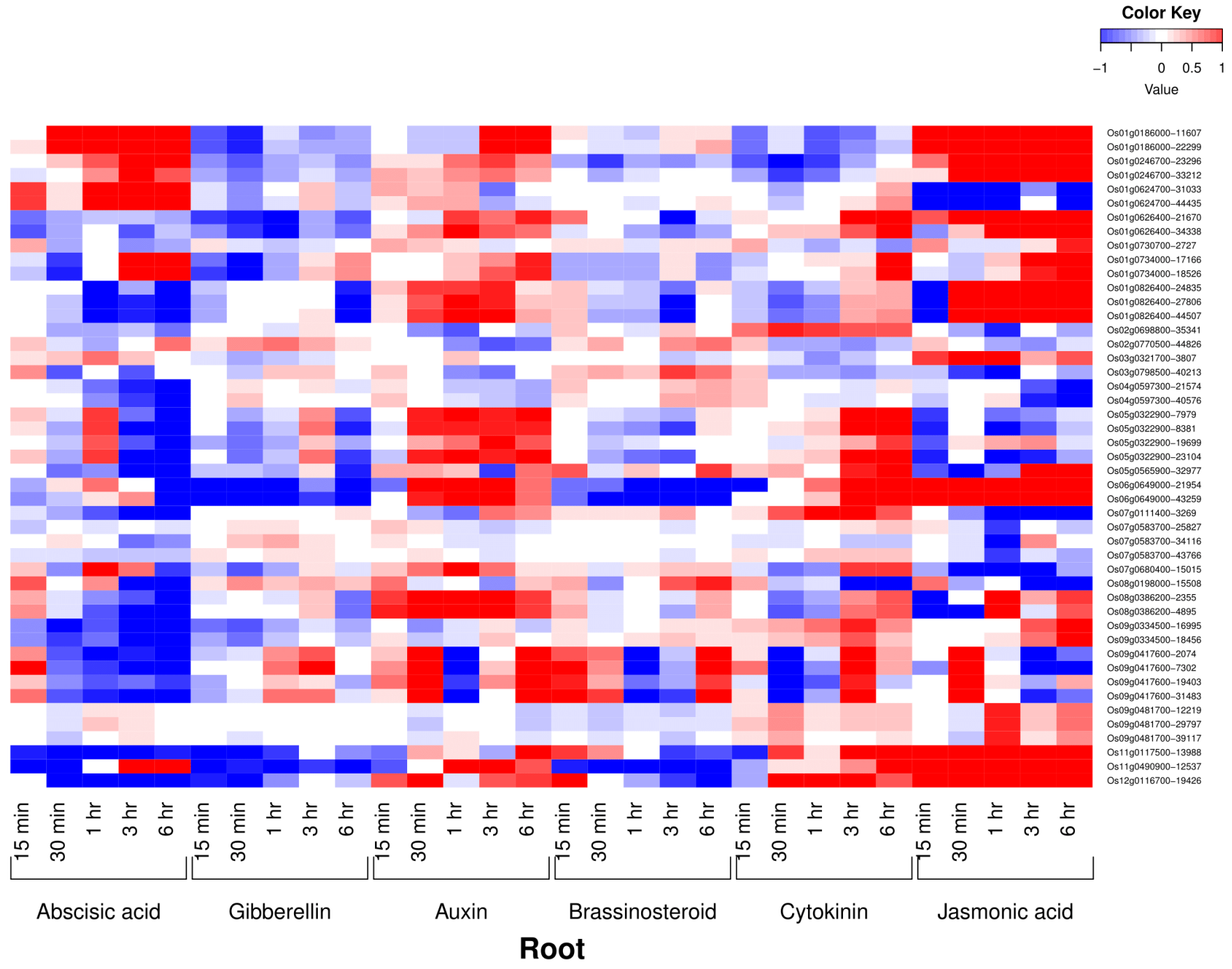

Figure 3. Heatmap showed the potential 26 AbSR-OsWRKY TF family members and their phytohormonal expression pattern in roots which are differentially regulated across the entire growth in the field conditions. The red color indicates up-regulation, the blue color indicates down-regulation, and the white color indicates no expression. The color bar at the right side top represents the level of expression value, where -1 and 1 represent down- and up-regulation respectively of AbS responsible OsWRKY TF family members.

\subsection{Phylogenetic Analysis of WRKY TFs}

Retrieved WRKY amino acid sequences were imported into MEGA v7.0 software (Philadelphia, PA, USA) and the unrooted phylogenetic tree was constructed by the maximum-likelihood method to study the evolutionary organization of the potential 26 WRKY TF family members (Figure 4). The unrooted tree confirmed the homology between the OsWRKY TF family members with SiWRKY, SbWRKY, and ZmWRKY using phylogenetic tree analysis. 
Table 2. Details of OsWRKY genes and their properties.

\begin{tabular}{|c|c|c|c|c|c|c|c|c|c|c|}
\hline S. No & Gene Name & RAP ID & Nt L & aa $L$ & M. Wt & pI & AI & II & GRAVY & SL \\
\hline 1 & OsWRKY1 & Os01g0246700 & 1275 & 425 & $45,967.1$ & 10.0694 & 68 & 40.54 & -0.383 & $\mathrm{Ct}$ \\
\hline 2 & OsWRKY 6 & Os03g0798500 & 741 & 247 & $26,500.7$ & 7.6528 & 68.21 & 55.29 & -0.549 & Cyto \\
\hline 3 & OsWRKY10 & Os01g0186000 & 825 & 275 & $29,056.4$ & 7.4157 & 60.33 & 43.9 & -0.4 & $\mathrm{~N}$ \\
\hline 4 & OsWRKY11 & Os01g0626400 & 1140 & 380 & 39,856 & 7.0634 & 49.45 & 63.38 & -0.731 & $\mathrm{~N}$ \\
\hline 5 & OsWRKY12 & Os01g0624700 & 738 & 246 & $25,832.6$ & 8.2902 & 54.37 & 43.51 & -0.424 & $\mathrm{Ct}$ \\
\hline 6 & OsWRKY14 & Os01g0730700 & 765 & 255 & $27,796.2$ & 6.9031 & 66.14 & 47.02 & -0.656 & $\mathrm{~N}$ \\
\hline 7 & OsWRKY23 & Os01g0734000 & 588 & 196 & $21,158.8$ & 9.4863 & 59.18 & 63.57 & -0.624 & $\mathrm{~N}$ \\
\hline 8 & OsWRKY 24 & Os01g0826400 & 1233 & 411 & $45,109.9$ & 4.6849 & 60 & 59.53 & -0.694 & $\mathrm{~N}$ \\
\hline 9 & OsWRKY28 & Os06g0649000 & 570 & 190 & $20,495.6$ & 8.492 & 64.07 & 50.13 & -0.375 & Cyto \\
\hline 10 & OsWRKY29 & Os07g0111400 & 1521 & 507 & $51,766.5$ & 6.1521 & 57.67 & 48.26 & -0.354 & $\mathrm{~N}$ \\
\hline 11 & OsWRKY32 & Os02g0770500 & 1071 & 357 & $36,383.7$ & 4.9404 & 56.83 & 55.42 & -0.431 & $\mathrm{~N}$ \\
\hline 12 & OsWRKY37 & Os04g0597300 & 945 & 315 & 32733.4 & 5.869 & 60.83 & 69.16 & -0.416 & $\mathrm{~N}$ \\
\hline 13 & OsWRKY45 & Os05g0322900 & 1545 & 515 & $53,042.3$ & 5.3217 & 57.43 & 47.7 & -0.415 & PM \\
\hline 14 & OsWRKY49 & Os05g0565900 & 585 & 195 & $21,400.7$ & 6.269 & 52.01 & 52.32 & -0.579 & $\mathrm{Ct}$ \\
\hline 15 & OsWRKY55 & Os03g0321700 & 996 & 332 & $34,901.2$ & 4.3811 & 57.73 & 65.5 & -0.507 & $\mathrm{~N}$ \\
\hline 16 & OsWRKY66 & Os02g0698800 & 1176 & 392 & $41,403.5$ & 6.1909 & 51.33 & 52.47 & -0.646 & $\mathrm{~N}$ \\
\hline 17 & OsWRKY71 & Os07g0583700 & 1857 & 619 & $66,163.6$ & 6.3317 & 58.75 & 51.59 & -0.683 & $\mathrm{~N}$ \\
\hline 18 & OsWRKY73 & Os07g0680400 & 1002 & 334 & $34,837.5$ & 6.5945 & 54.26 & 70.97 & -0.471 & $\mathrm{~N}$ \\
\hline 19 & OsWRKY74 & Os08g0198000 & 2586 & 862 & $97,370.3$ & 6.4311 & 80.14 & 41.56 & -0.41 & $\mathrm{~N}$ \\
\hline 20 & OsWRKY79 & Os08g0386200 & 960 & 320 & $33,550.3$ & 6.6611 & 67.4 & 41.48 & -0.316 & $\mathrm{~N}$ \\
\hline 21 & OsWRKY82 & Os09g0334500 & 1086 & 362 & $37,944.1$ & 6.4041 & 64.21 & 53.99 & -0.428 & $\mathrm{~N}$ \\
\hline 22 & OsWRKY83 & Os09g0417600 & 984 & 328 & $34,780.2$ & 8.0535 & 68.69 & 50.66 & -0.496 & $\mathrm{~N}$ \\
\hline 23 & OsWRKY85 & Os09g0481700 & 1902 & 634 & $68,280.1$ & 6.0112 & 51.66 & 64.68 & -0.712 & $\mathrm{~N}$ \\
\hline 24 & OsWRKY92 & Os11g0117500 & 963 & 321 & $35,915.9$ & 6.417 & 72.25 & 58.59 & -0.672 & $\mathrm{~N}$ \\
\hline 25 & OsWRKY94 & Os11g0490900 & 729 & 243 & $25,857.2$ & 9.3347 & 46.45 & 55.93 & -0.778 & $\mathrm{~N}$ \\
\hline 26 & OsWRKY101 & Os12g0116700 & 966 & 322 & $35,749.5$ & 6.3705 & 69.31 & 60.38 & -0.723 & $\mathrm{~N}$ \\
\hline
\end{tabular}

Nt L, Nucleotide length; aa L, amino acid length; M. Wt, Molecular weight; pI, Isoelectric point; AI, Aliphatic index; II, Instability index; GRAVY, Grand average of hydropathicity, SL, Subcellular localization; Cyto, Cytosol; Ct, Chloroplast; N, Nucleus; PM, Plasma membrane.

\subsection{Gene Organization Analysis}

Gene structure analysis revealed the number and distribution of exons and introns in the OsWRKY TF genes (Figure 5). The distribution of introns ranged from one to seven amid exonic sequences which may be due to evolutionary changes that have occurred in the OsWRKY TF family members. The majority of the genes contained two introns, whereas six genes (OsWRKY14, OsWRKY23, OsWRKY55, OsWRKY79, OsWRKY83, and OsWRKY94) had only one intron. A maximum of seven introns was found to be present in OsWRKY1 (Figure 5).

\subsection{Functional GO Analysis of OsWRKY TFs}

OsWRKY TF genes and their functional ontology were predicted by the ShinyGO database which showed the involvement of these genes in various biological processes and molecular functions. OsWRKY novel candidate genes were imputed to be involved in stimulus, chemical, regulation of transcription, metabolic and biosynthetic processes (Figure 6). The significant molecular functions of these candidate genes were encoded for different types of sequence-specific, DNA, heterocyclic and regulatory region binding activities (Figure 7). 


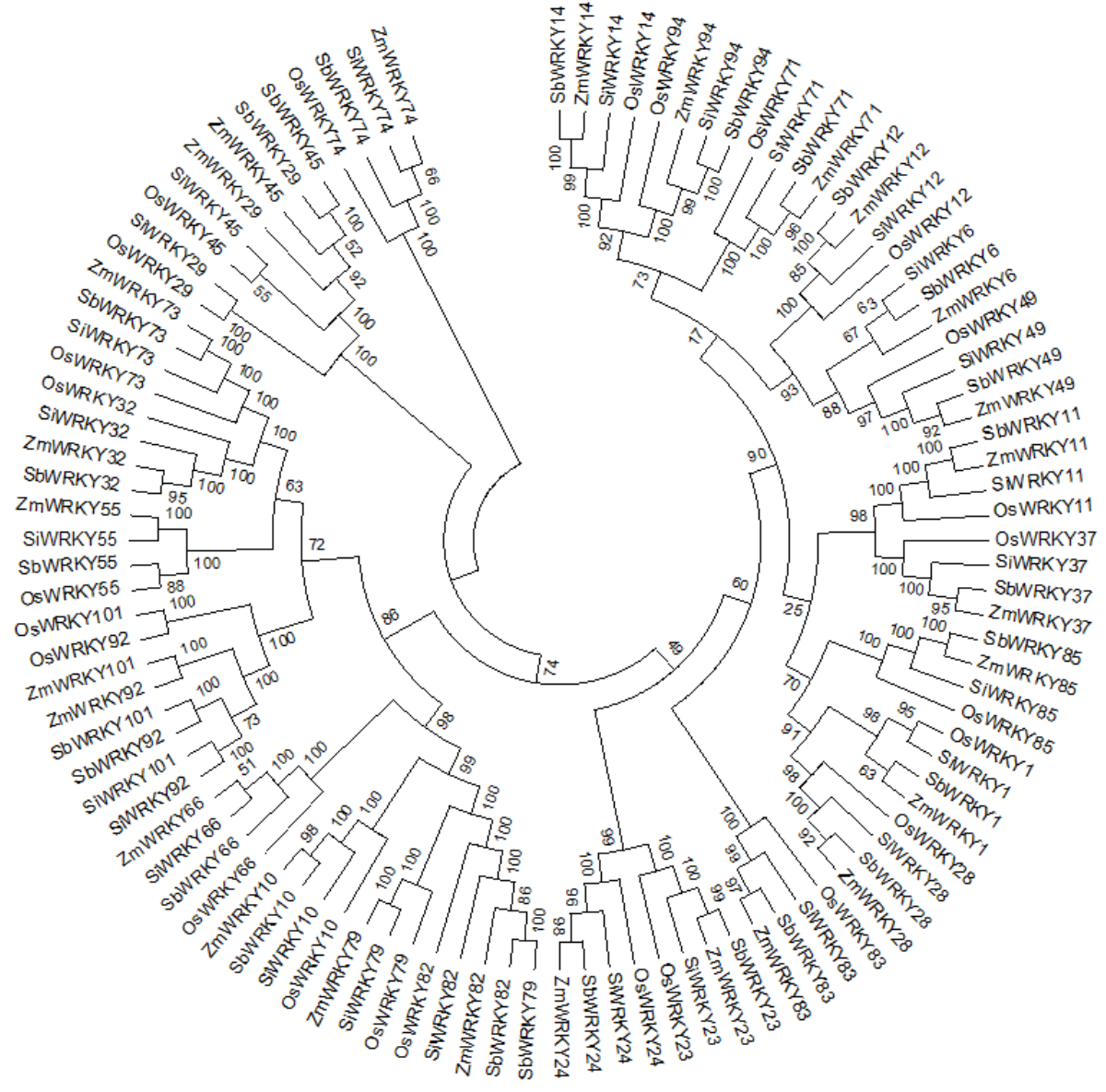

Figure 4. Phylogenetic relationships of 26 potential OsWRKY genes of O. sativa, S. italica, S. bicolor, and Z. mays. The amino acid sequences were aligned by ClustalW at the MEGA v7.0 program with the unrooted maximum likelihood method. The evolutionary tree was constructed with bootstrap confidence values from 1000 iterations.

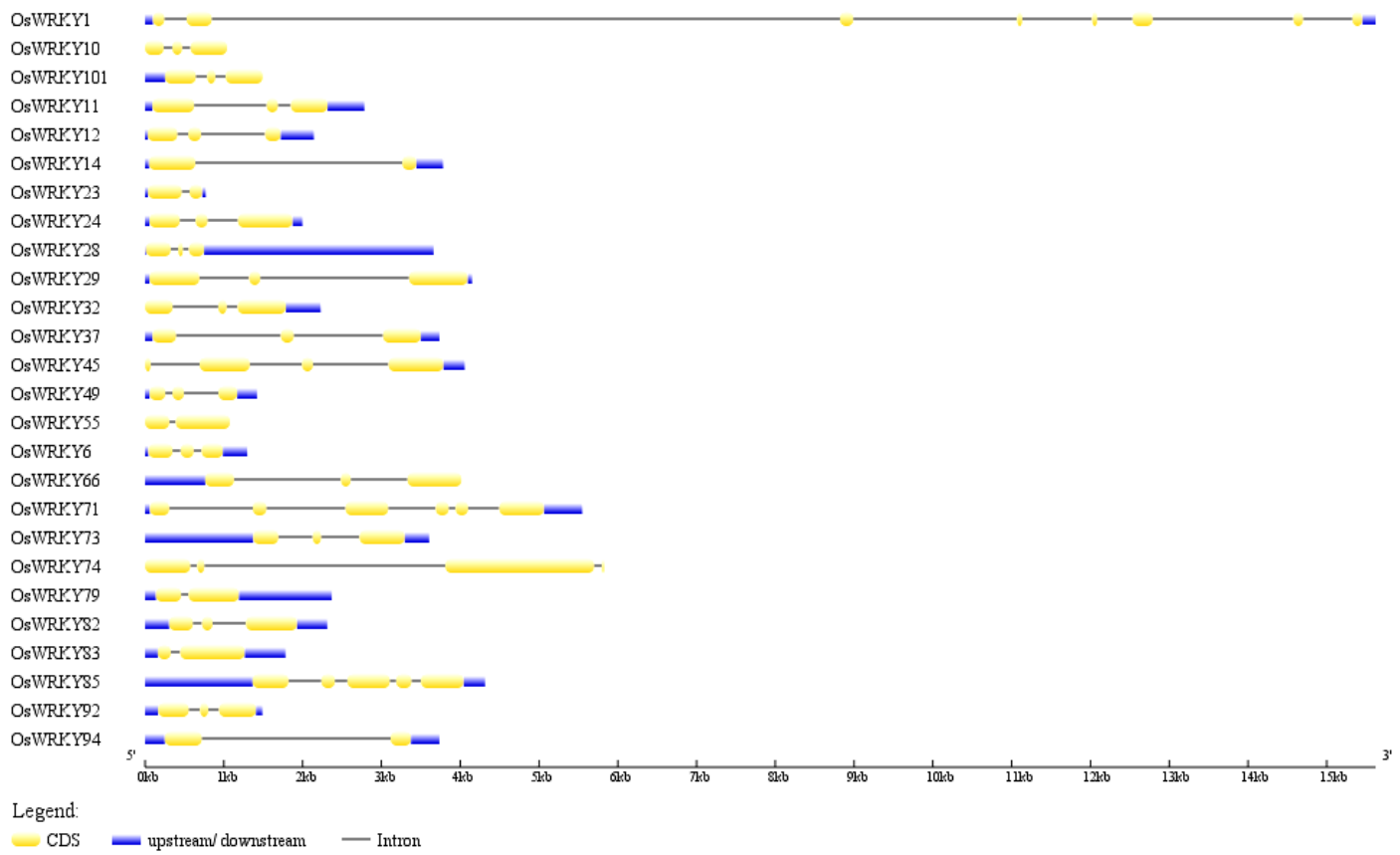

Figure 5. Structural organization of OsWRKY TF genes. Introns, exons, and untranslated regions (UTR) are represented by black lines, yellow, and blue rectangles. The scale bar denotes the size of the gene. 


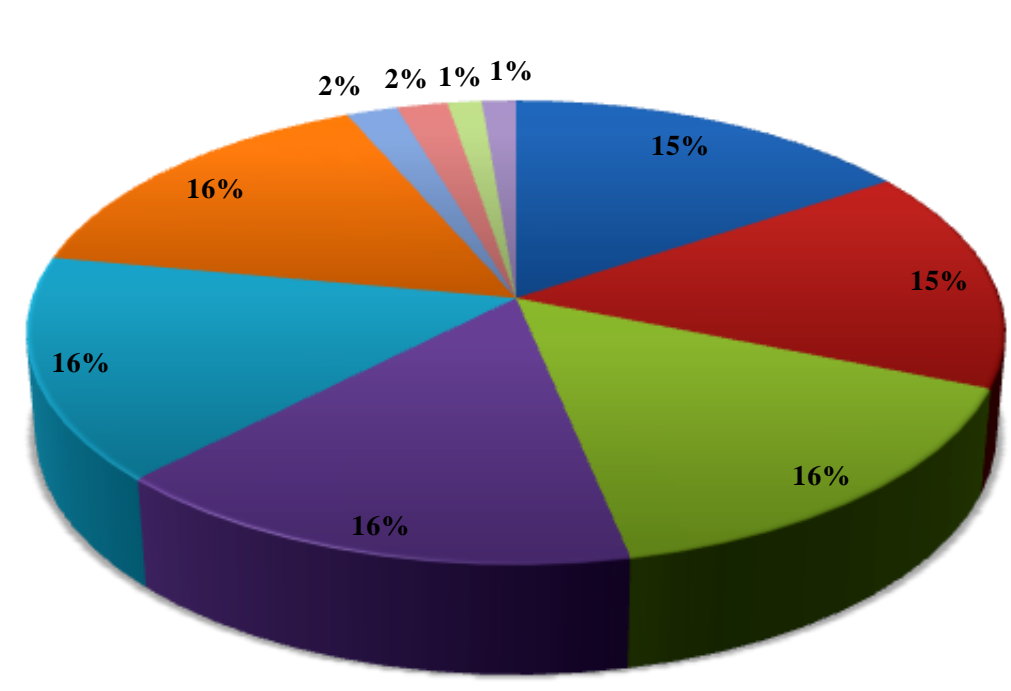

Biosynthetic process

$\square$ Regulation of metabolic process

$\square$ Regulation of biological process

$\square$ Regulation of cellular process

$\square$ Biological regulation

$\square$ DNA-binding transcription factor activity

$\square$ Response to chemical

$\square$ Response to stimulus

$\square$ Response to endogenous stimulus

$\square$ Positive regulation of biological process

Figure 6. OsWRKY genes and their biological functions. The biological function was imputed according to the significance level ( $p$-value FDR cutoff).

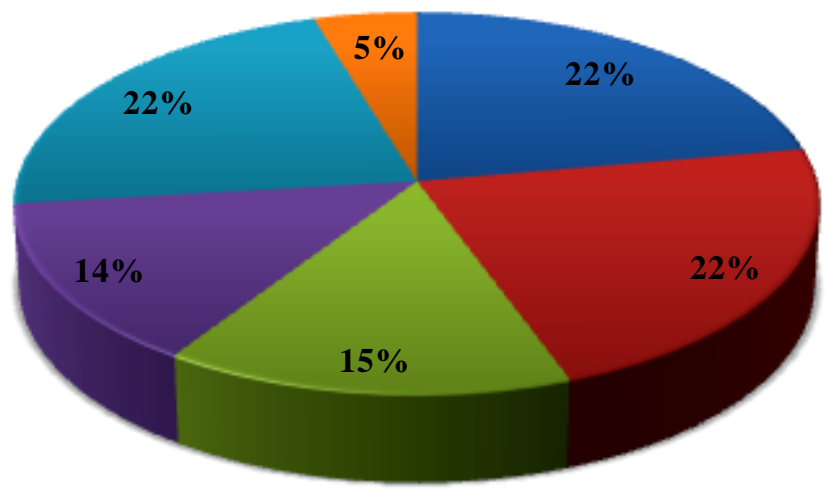

\section{DNA binding}

$\square$ Transcription regulator activity

\section{Ion binding}

\section{Protein binding}

\section{$\square$ Seuence specific DNA binding}

\section{$\square$ Organic cyclic compound binding}

Figure 7. OsWRKY genes and their molecular function. The molecular function was imputed according to the significance level ( $p$-value FDR cut-off).

\subsection{OsWRKY Gene Interaction Network Analysis}

Potential 26 WRKY TF family encoding genes were obtained from O. sativa ssp. Japonica AbSR OSWRKY TF genes and molecular interaction network was analyzed using the STRING $v 11.0$ database. The gene network had 46 nodes, 74 weighted edges, and an enrichment $p$-value score $<0.01$ (Figure 8 ). The average nodal degree between the neighboring genes was 3.22. This interaction network revealed the complexity of AbSR OsWRKY, hence it proved the nature of multi-gene.

\subsection{Orthologous Relationships of OsWRKY Genes}

Gramene-BLASTP analysis revealed chromosomal collinearity among 26 potential OsWRKY genes with those of C4 panicoid grass species such as S. italica, S. bicolour, and $Z$. mays. The chromosomal ideogram exhibited the maximum relationship that occurred between O. sativa and C4 grass plant species [26 OsWRKY (100\%)] (Figure 9A-C; Supplementary Tables S4-S6). 


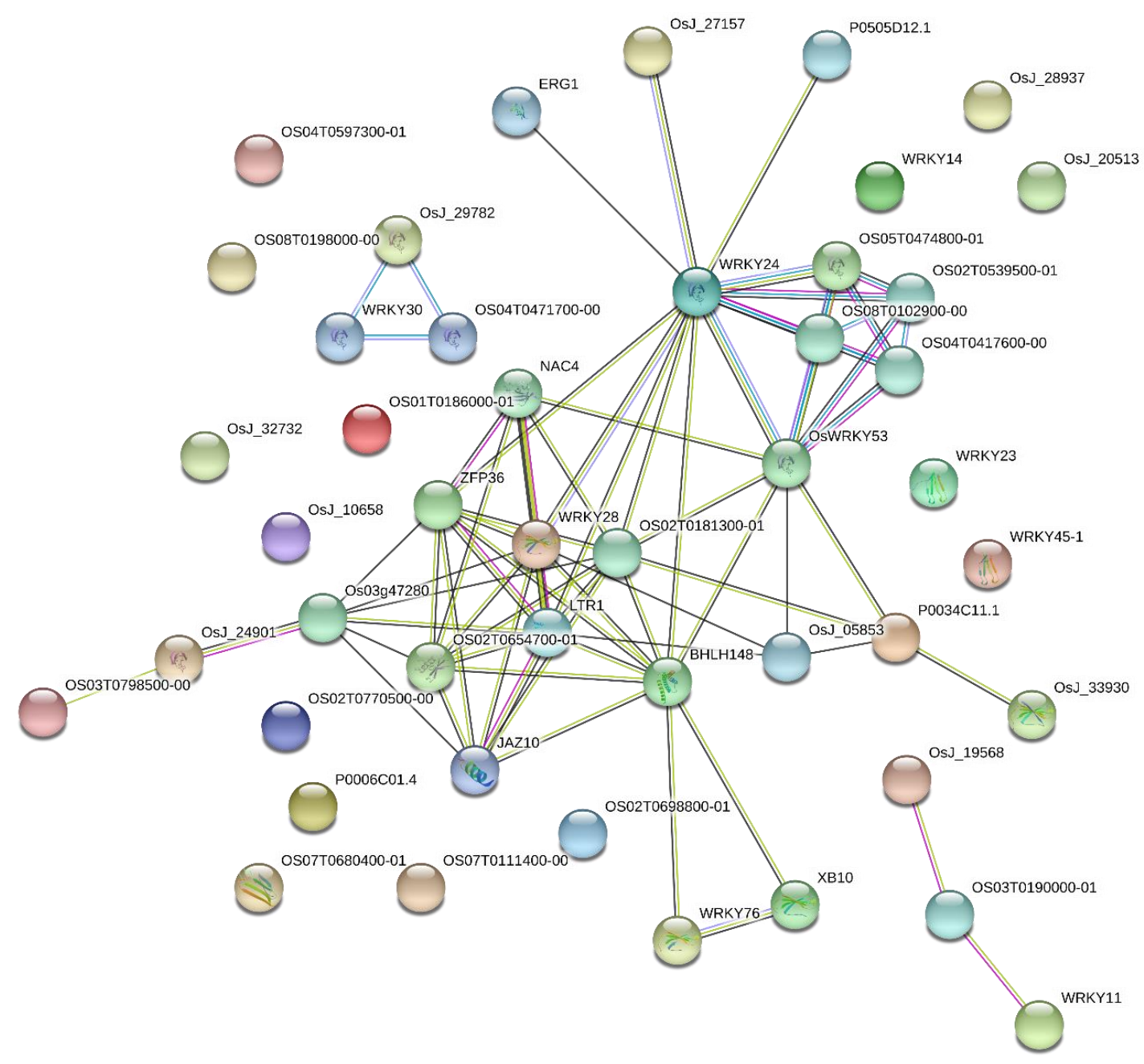

Figure 8. Molecular interaction network of 26 OsWRKY genes involved in various stress responses. The line thickness denotes the level of interaction between genes and colored lines between the genes denote various types of the interaction network. Black color, gene co-occurrence; red color, gene fusion; pink color, experimentally determined; violet color, gene homology; green color, gene neighborhood; blue color, gene co-occurrence. Gene nodes containing ribbon structures represent the presence of gene $3 \mathrm{D}$ structural information.
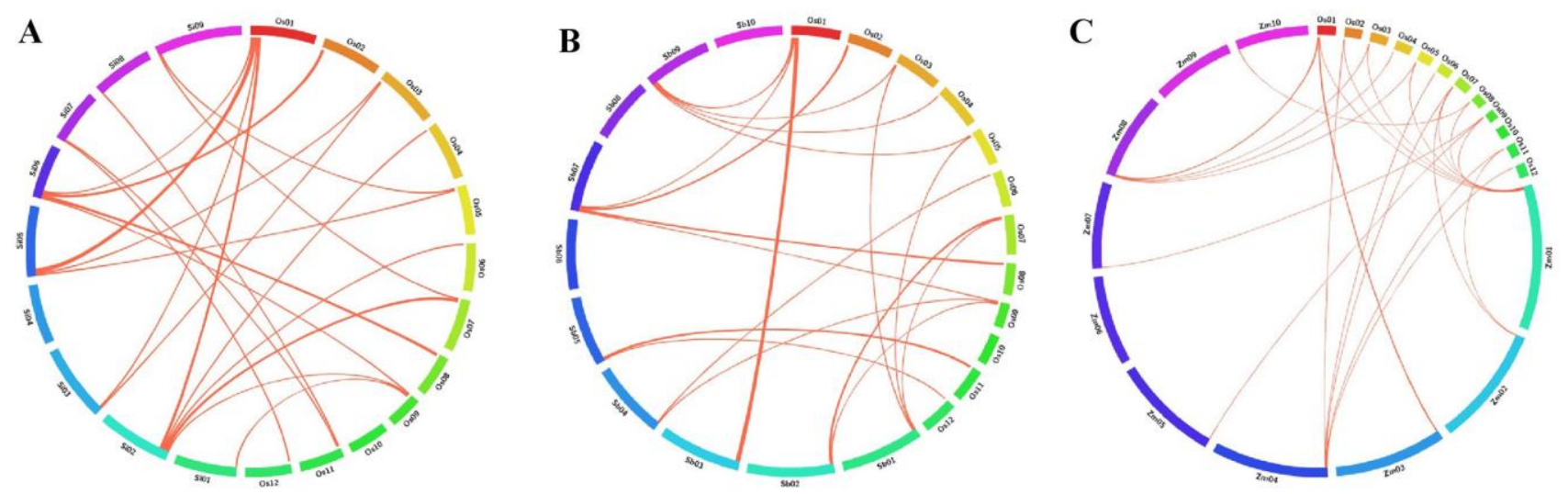

Figure 9. Comparative orthologous relationship of WRKY genes among (A) rice and foxtail millet, (B) rice and sorghum, (C) rice and maize. All segments denote chromosome and red links represent the genomic regions with a corresponding target chromosome. 


\section{Discussion}

WRKY TFs are a class of DNA-binding proteins that play a major role in physiological processes, plant growth and development, signal transduction, senescence, seed dormancy, responses to a diverse biotic and AbS, biosynthesis and hormonal regulations and stress signaling through auto- and cross-regulation [63-65]. Compared to biotic stresses, so far, only limited information is available on the WRKY TF family members' role in AbS. Considering the importance of WRKY TF genes from various plant species and their crucial roles under various environmental conditions, it remains a big challenge to unveil their mechanisms in AbS. The functions of WRKY TF genes in defense signal transduction pathways came from the analysis of dicot plants, such as tomato, Arabidopsis, potato, and tobacco, and to date, less information was reported in rice and other monocot plants. Few studies have demonstrated that many WRKY genes are predominantly expressed in response to AbS such as cold, salinity, drought, flooding and submergence [66,67], extreme levels of light (high and low), sugar starvation [63], phosphate deprivation [68], radiation (UV-B and UV-A) [69], and wounding [70]. However, the mode of action of WRKY TFs among the diverse signaling pathways and self-regulation is still not clearly understood.

The regulation and fine-tuning of WRKY TFs during plant stress responses contribute to the establishment of complex signaling networks and their crucial roles in plant $\mathrm{AbS}$ responses that make them potential candidates for imparting stress tolerance. More than 100 WRKY genes were predicted in rice [71]. They are upregulated in response to salinity, drought, and ABA, and downregulated in response to cold [71,72]. However, out of the extensive list of rice WRKY TFs studied, only a few genes have been functionally characterized with their response to AbS. The overexpression of OsWRKY genes, known to increase the sensitivity to cold and salt stresses [73], involved in the ABA signaling [12], enhanced drought and heat tolerance after heat pre-treatment as compared to wild-type plants [74]. When OsWRKY genes were over-expressed in Arabidopsis, besides an improvement of lateral root number and primary root length in the transgenic plants under osmotic stress, no clear phenotype regarding survival under AbS was shown [48,75] and increased sensitivity to ABA, salt, and osmotic stress [63]. The overexpression of OsWRKY TFs has induced higher sensitivity or enhanced stress tolerance, thus acting as both positive and negative regulators in stress signaling pathways [76].

This study is the foremost one to report an integrated genome-transcriptome-wide systematic analysis in $C_{3}$ model plant rice and also $C_{4}$ grass species. A deeper view of its importance in rice stress and systems biology particularly on AbS was investigated to identify and annotate the key players by computational omics approaches and examine their orthologs, differential expression signatures of spatio-temporal and plant hormones levels, interactome map, and molecular properties of the WRKY TFs in response to AbS. The systematic analysis provides insights for the molecular basis of WRKY TFs in O. sativa to stress responses, notably on plant AbS tolerance.

Based on the publicly available RNA-seq transcriptome data of OsWRKY genes, 26 out of 104 OsWRKY TFs showed a high and low level of hormonal expression. This expression signature data revealed that 26 potential OsWRKY genes for phytohormones such as ABA, JA, auxin, GA, CK, and BRs in the root and shoot of the rice plant at various time points. Thus, the obtained results revealed the lower expression of auxin and JA under field conditions. On the other hand, under a stressful environment, these two hormones are expressed in elevated levels and they play an important role in biotic and AbS conditions. From the heat map analysis, 26 potentially expressed AbSR OsWRKY TF genes were used for further functional analysis.

Spatio-temporal expression profiling of 26 OsWRKY genes showed the differential expression in 48 different tissue/organ-specific and developmental stages at individual abiotic stress conferring the higher expression level of OsWRKY genes from various tissuespecific and organs-specific expression dynamism under field conditions. This analysis revealed that OsWRKY TFs could be potential candidates for further functional characterization and distinct expression patterns for explaining their roles in AbS signaling. Further, 
this data provides the support for conducting overexpression studies and metabolic engineering in different plant tissues in order to increase the number of AbSR gene content and also to enhance the nutrition content in rice. Moreover, the properties of the genes have many differences in M.Wt, amino acid length, aliphatic index, and $\mathrm{pI}$ of these genes which contain novel variants, which need to be delineated further for validation.

A phylogenetic tree of OsWRKY and WRKY TFs from C4 plants such as SiWRKY, $S b W R K Y$, and ZmWRKY was constructed in accordance with the multiple sequence alignment of their corresponding WRKY domains. The position of WRKY DNA—binding domain (WRKY) and hAT family C-terminal dimerization domain (Dimer_Tnp_hAT) in OsWRKY, SiWRKY, SbWRKY, and ZmWRKY have been analyzed by HMMSCAN. This unrooted tree showed the distribution and divergence of WRKY domains and conserved regions present in candidate genes. Phylogenetic analysis showed that the predicted gene sequences highly diverge to S. italica, S. bicolor, and Z. mays. OsWRKY and their respective molecular cross-talks and functional relationships unraveled the complexity of unique and combined abiotic stress upon evolutionary seed gene modules and their connecting nodes, edges, and genes that were expressed in AbS studies [4,77].

Comparative mapping of WRKY and their respective genes on rice, sorghum, maize, and foxtail millet were performed to unveil the collinearity between the rice and $\mathrm{C}_{4}$ grass species. OsWRKY showed maximum orthology of genes with S. italica, Z. mays, and S. bicolor owing to their wide range of chromosomal synteny. This analysis clearly shows that OsWRKY genes are highly similar to SbWRKY, SiWRKY, and ZmWRKY TFs and this close evolutionary relationship revealed the putative novel variants about $C_{3}$ and $C_{4}$ model crop plants, particularly grass species. This gene synteny information could pave the way for understanding the molecular evolutionary analysis and also could be used to conduct the over-expression and molecular breeding studies of OsWRKY genes among Poaceae members.

Comparing with rice (104 WRKYs), Arabidopsis (Arabidopsis thaliana) and wheat (Triticum aestivum) contains a proportionate number of WRKY genes (72 AtWRKYs and 171 TaWRKYs) [78,79], among which a certain number of genes play an important role in AbS. Drought is one of the most common AbS, that has a severe impact on crop growth and yield [80]. Rice OsWRKY11 and OsWRKY72 play an important role in drought tolerance $[81,82]$ in analogous with Arabidopsis genes such as AtWRKY57, AtWRKY63 [83,84], and wheat genes TaWRKY14, TaWRKY90, TaWRKY8, TaWRKY122, and TaWRKY45 [85]. In addition, 12 TaWRKYs were recognized as the candidate drought-responsive genes, which are orthologous to genes in Arabidopsis and enhances during water deprivation [78]. Thus, the characterization of WRKYs in rice will help to unravels the AbS associated regulatory networks.

\section{Conclusions}

In this study, we have identified 26 OsWRKY genes that are responsible for various AbS via the computational systems biology approach. The gene properties, evolutionary analysis, gene structure, gene ontology annotation, and gene interaction networks of OsWRKY were evaluated. OsWRKY TFs and their spatio-temporal and phytohormonal expression of these candidate genes showed their differential expression signatures in various rice plant tissues and plant growth hormones, respectively. In addition to that, comparative mapping analysis exhibited that the maximum similarity with $C_{4}$ grass species such as S. italica, S. bicolor, and Z. mays. Thus, provides an important indication of their regulatory functions in AbS stress conditions. This study also provides depth information about OsWRKY TF genes and delineates the plant developmental metabolisms and their functional regulations under AbS conditions. This holistic study also hypothesizes that the identified candidate players may interact with various stress responsible TF family members and activates the transcriptional regulation, antioxidant enzymes, ROS scavenging mechanisms, biosynthesis of amino acids, cellular and physiological processes, and 
synthesis of polyamines in response to AbS tolerance. Further functional analyses are needed to unravel the novel avenues of the identified players.

Supplementary Materials: The following are available online at https:/ /www.mdpi.com/article/10. 3390/agronomy11071301/s1, Figure S1: Meta expression analysis of 104 OsWRKY TF genes, Table S1: WRKY name and NCBI ID in C3 and C4 grass plants; Table S2: OsWRKY genes and their HMMSCAN report; Table S3: OsWRKY genes and their attributes; Table S4: Orthologous relationship between O. sativa and S. italica; Table S5: Orthologous relationship between O. sativa and S. bicolor; Table S6: Orthologous relationship between $O$. sativa and $Z$. mays.

Author Contributions: Conceptualization, R.J. and P.M.; Data curation, L.S.; Investigation, R.J., P.M., L.S., S.A. (Sivakumar Adarshan), M.A.L. and S.K.P.; Supervision, M.R.; Validation, J.-T.C. and S.A. (Sunny Ahmar); Writing—original draft, R.J. and P.M.; Writing—review \& editing, J.-T.C., S.A. (Sunny Ahmar), X.W., F.M.-P. and M.R. All authors have read and agreed to the published version of the manuscript.

Funding: The study was financially supported by the Chilean National Fund for Scientific and Technological Development (FONDECYT) grant number 1201973.

Institutional Review Board Statement: Not applicable.

Informed Consent Statement: Not applicable.

Data Availability Statement: Data used in this study are presented in the Supplementary Materials.

Acknowledgments: RJ acknowledges RUSA 2.0 (Alu/RUSA/Project Fellow-Science-TBRP/2019 dated 07.03.2019), Alagappa University, Karaikudi, Tamil Nadu, India for providing Research Fellowship in the form of Project Fellow. The authors thankfully acknowledge DST-FIST (Grant No. SR/FST/LSI-639/2015(C)), UGC-SAP (Grant No.F.5-1/2018/DRS-II (SAP-II)) and DST-PURSE (Grant No. SR/PURSE Phase 2/38 (G)) for providing instrumentation facilities. The authors also thank RUSA 2.0 [F. 24-51/2014-U, Policy (TN Multi-Gen), Dept of Edn, GoI].

Conflicts of Interest: The authors declare no conflict of interests.

\section{Abbreviations}

AbS-Abiotic Stress; CAbS-Combined Abiotic Stresses; Os—Oryza sativa; OsWRKY—Oryza sativa WRKY; SbWRKY —Sorghum bicolor WRKY; SiWRKY—Setaria italica WRKY; ZmWRKY—Zea mays WRKY.

\section{References}

1. Calicioglu, O.; Flammini, A.; Bracco, S.; Bellù, L.; Sims, R. The Future Challenges of Food and Agriculture: An Integrated Analysis of Trends and Solutions. Sustainability 2019, 11, 222. [CrossRef]

2. Mickelbart, M.V.; Hasegawa, P.M.; Bailey-Serres, J. Genetic Mechanisms of Abiotic Stress Tolerance that Translate to Crop Yield Stability. Nat. Rev. Genet. 2015, 16, 237. [CrossRef]

3. Muthuramalingam, P.; Jeyasri, R.; Kalaiyarasi, D.; Pandian, S.; Krishnan, S.R.; Satish, L.; Pandian, S.K.; Ramesh, M. Emerging Advances in Computational Omics Tools for Systems Analysis of Gramineae Family Grass Species and Their Abiotic Stress Responsive Functions. OMICS-Based Approach Plant. Biotechnol. 2019, 185, 185.

4. Muthuramalingam, P.; Krishnan, S.R.; Pandian, S.; Mareeswaran, N.; Aruni, W.; Pandian, S.K.; Ramesh, M. Global Analysis of Threonine Metabolism Genes Unravel Key Players in Rice to Improve the Abiotic Stress Tolerance. Sci. Rep. 2018, 8, 9270. [CrossRef]

5. Muthuramalingam, P.; Jeyasri, R.; Bharathi, R.K.A.S.; Suba, V.; Pandian, S.T.K.; Ramesh, M. Global Integrated Omics Expression Analyses of Abiotic Stress Signaling HSF Transcription Factor Genes in Oryza Sativa L.: An in Silico Approach. Genomics 2020, 112, 908-918. [CrossRef]

6. Yamaguchi-Shinozaki, K.; Shinozaki, K. Transcriptional Regulatory Networks in Cellular Responses and Tolerance to Dehydration and Cold Stresses. Annu. Rev. Plant. Biol. 2006, 57, 781-803. [CrossRef]

7. Tran, L.S.; Nakashima, K.; Shinozaki, K.; Yamaguchi-Shinozaki, K. Plant Gene Networks in Osmotic Stress Response: From Genes to Regulatory Networks. Methods Enzymol. 2007, 428, 109-128.

8. Udvardi, M.K.; Kakar, K.; Wandrey, M.; Montanari, O.; Murray, J.; Andriankaja, A.; Zhang, J.Y.; Benedito, V.; Hofer, J.M.I.; Chueng, F.; et al. Legume Transcription Factors: Global Regulators of Plant Development and Response to the Environment. Plant Physiol. 2007, 144, 538-549. [CrossRef] 
9. Jin, J.; Zhang, H.; Kong, L.; Gao, G.; Luo, J. PlantTFDB 3.0: A Portal for the Functional and Evolutionary Study of Plant Transcription Factors. Nucleic Acids Res. 2013, 42, 182-187. [CrossRef]

10. Dong, J.; Chen, C.; Chen, Z. Expression Profiles of the Arabidopsis WRKY Gene Superfamily during Plant Defense Response. Plant. Mol. Biol. 2003, 51, 21-37. [CrossRef]

11. Eulgem, T.; Rushton, P.J.; Robatzek, S.; Somssich, I.E. The WRKY Superfamily of Plant Transcription Factors. Trends Plant. Sci. 2000, 5, 199-206. [CrossRef]

12. Xie, Z.; Zhang, Z.L.; Zou, X.; Huang, J.; Ruas, P.; Thompson, D.; Shen, Q.J. Annotations and Functional Analyses of the Rice WRKY Gene Superfamily Reveal Positive and Negative Regulators of Abscisic Acid Signaling in Aleurone Cells. Plant Physiol. 2005, 137, 176-189. [CrossRef] [PubMed]

13. Sun, C.; Palmqvist, S.; Olsson, H.; Borén, M.; Ahlandsberg, S.; Jansson, C. A Novel WRKY Transcription Factor, SUSIBA2, Participates in Sugar Signaling in Barley by Binding to the Sugar-Responsive Elements of the Iso1 Promoter. Plant Cell 2003, 15, 2076-2092. [CrossRef]

14. Guan, Y.; Meng, X.; Khanna, R.; LaMontagne, E.; Liu, Y.; Zhang, S. Phosphorylation of a WRKY Transcription Factor by MAPKs Is Required for Pollen Development and Function in Arabidopsis. PLoS Genet. 2014, 10, e1004384. [CrossRef]

15. Ding, Z.J.; Yan, J.Y.; Xu, X.Y.; Yu, D.Q.; Li, G.X.; Zhang, S.Q.; Zheng, S.J. Transcription Factor WRKY 46 Regulates Osmotic Stress Responses and Stomatal Movement Independently in Arabidopsis. Plant J. 2014, 79, 13-27. [CrossRef] [PubMed]

16. Johnson, C.S.; Kolevski, B.; Smyth, D.R. TRANSPARENT TESTA GLABRA2, a Trichome and Seed Coat Development Gene of Arabidopsis, Encodes a WRKY Transcription Factor. Plant J. 2002, 14, 1359-1375. [CrossRef]

17. Luo, M.; Dennis, E.S.; Berger, F.; Peacock, W.J.; Chaudhury, A. MINISEED3 (MINI3), a WRKY Family Gene, and HAIKU2 (IKU2), a Leucine-Rich Repeat (LRR) KINASE Gene, Are Regulators of Seed Size in Arabidopsis. Proc. Natl. Acad. Sci. USA 2005, 102, 17531-17536. [CrossRef]

18. Cai, Y.; Chen, X.; Xie, K.; Xing, Q.; Wu, Y.; Li, J.; Du, C.; Sun, Z.; Guo, Z. Dlf1, a WRKY Transcription Factor, Is Involved in the Control of Flowering Time and Plant Height in Rice. PLoS ONE 2014, 9, e102529. [CrossRef] [PubMed]

19. Alexandrova, K.S.; Conger, B.V. Isolation of Two Somatic Embryogenesis-Related Genes from Orchardgrass (Dactylis glomerata). Plant. Sci. 2002, 162, 301-307. [CrossRef]

20. Lagacé, M.; Matton, D.P. Characterization of a WRKY Transcription Factor Expressed in Late Torpedo-Stage Embryos of Solanum Chacoense. Planta 2004, 219, 185-189. [CrossRef]

21. Wang, H.; Avci, U.; Nakashima, J.; Hahn, M.G.; Chen, F.; Dixon, R.A. Mutation of WRKY Transcription Factors Initiates Pith Secondary Wall Formation and Increases Stem Biomass in Dicotyledonous Plants. Proc. Natl. Acad. Sci. USA 2010, 107, 22338-22343. [CrossRef]

22. Yu, Y.; Hu, R.; Wang, H.; Cao, Y.; He, G.; Fu, C.; Zhou, G. MIWRKY12, a Novel Miscanthus Transcription Factor, Participates in Pith Secondary Cell Wall Formation and Promotes Flowering. Plant. Sci. 2013, 212, 1-9. [CrossRef]

23. Xu, Y.H.; Wang, J.W.; Wang, S.; Wang, J.Y.; Chen, X.Y. Characterization of GaWRKY1, a Cotton Transcription Factor that Regulates the Sesquiterpene Synthase Gene (+)- $\delta$-cadinene Synthase-A. Plant Physiol. 2004, 135, 507-515. [CrossRef]

24. Ma, D.; Pu, G.; Lei, C.; Ma, L.; Wang, H.; Guo, Y.; Chen, J.; Du, Z.; Wang, H.; Li, G.; et al. Isolation and Characterization of AaWRKY1, an Artemisia Annua Transcription Factor that Regulates the Amorpha-4, 11-Diene Synthase Gene, a Key Gene of Artemisinin Biosynthesis. Plant. Cell Physiol. 2009, 50, 2146-2161. [CrossRef]

25. Suttipanta, N.; Pattanaik, S.; Kulshrestha, M.; Patra, B.; Singh, S.K.; Yuan, L. The Transcription Factor Crwrky1 Positively Regulates the Terpenoid Indole Alkaloid Biosynthesis in Catharanthus Roseus. Plant Physiol. 2011, 157, 2081-2093. [CrossRef]

26. Zhang, Z.L.; Xie, Z.; Zou, X.; Casaretto, J.; Ho, T.H.D.; Shen, Q.J. A Rice WRKY Gene Encodes a Transcriptional Repressor of the Gibberellin Signaling Pathway in Aleurone Cells. Plant Physiol. 2004, 134, 1500-1513. [CrossRef]

27. Robatzek, S.; Somssich, I.E. A New Member of the Arabidopsis WRKY Transcription Factor Family, Atwrky6, Is Associated with Both Senescence-and Defence-Related Processes. Plant J. 2001, 28, 123-133. [CrossRef]

28. Robatzek, S.; Somssich, I.E. Targets of AtWRKY6 Regulation during Plant Senescence and Pathogen Defense. Genes Dev. 2002, 16, 1139-1149. [CrossRef]

29. Miao, Y.; Laun, T.; Zimmermann, P.; Zentgraf, U. Targets of the WRKY53 Transcription Factor and Its Role during Leaf Senescence in Arabidopsis. Plant. Mol. Biol. 2004, 55, 853-867. [CrossRef]

30. Muthuramalingam, P.; Jeyasri, R.; Krishnan, S.R.; Pandian, S.T.K.; Sathishkumar, R.; Ramesh, M. Integrating the Bioinformatics and Omics Tools for Systems Analysis of Abiotic Stress Tolerance in Oryza sativa (L.). In Advances in Plant Transgenics: Methods and Applications; Sathishkumar, R., Kumar, S., Hema, J., Baskar, V., Eds.; Springer: Singapore, 2019; pp. 59-77.

31. Tang, J.; Wang, F.; Wang, Z.; Huang, Z.; Xiong, A.; Hou, X. Characterization and Co-Expression Analysis of WRKY Orthologs Involved in Responses to Multiple Abiotic Stresses in Pak-Choi (Brassica campestris Ssp. Chinensis). BMC Plant Biol. 2013, 13, 188. [CrossRef]

32. Muthuramalingam, P.; Krishnan, S.R.; Saravanan, K.; Mareeswaran, N.; Ramesh, M. Genome Wide Identification of Effective Transcription Factor Gene Families in Rice Identifies Potential Candidates Involved in Abiotic Stress Signaling. J. Plant. Biochem. Biot. 2018, 27, 300-317. [CrossRef]

33. Kim, C.Y.; Lee, S.H.; Park, H.C.; Bae, C.G.; Cheong, Y.H.; Choi, Y.J.; Han, C.D.; Lee, S.Y.; Lim, C.O.; Cho, M.J. Identification of Rice Blast Fungal Elicitor-Responsive Genes by Differential Display Analysis. Mol. Plant. Microbe Interact. 2000, 13, 470-474. [CrossRef] 
34. Asai, T.; Tena, G.; Plotnikova, J.; Willmann, M.R.; Chiu, W.L.; Gomez-Gomez, L.; Boller, T.; Ausubel, F.M.; Sheen, J. MAP Kinase Signalling Cascade in Arabidopsis Innate Immunity. Nature 2002, 415, 977. [CrossRef] [PubMed]

35. Rizhsky, L.; Davletova, S.; Liang, H.; Mittler, R. The Zinc Finger Gene Zat12 Is Required for Cytosolic Ascorbate Peroxidase 1 Expression during Oxidative Stress in Arabidopsis. J. Biol. Chem. 2004, 279, 11736-11743. [CrossRef]

36. Seki, M.; Narusaka, M.; Ishida, J.; Nanjo, T.; Fujita, M.; Oono, Y.; Kamiya, A.; Nakajima, M.; Enju, A.; Sakurai, T.; et al. Monitoring the Expression Profiles of 7000 Arabidopsis Genes under Drought, Cold and High-Salinity Stresses Using a Full-Length Cdna Microarray. Plant J. 2002, 31, 279-292. [CrossRef]

37. Hara, K.; Yagi, M.; Kusano, T.; Sano, H. Rapid Systemic Accumulation of Transcripts Encoding a Tobacco WRKY Transcription Factor upon Wounding. Mol. Genet. Genom. 2000, 263, 30-37. [CrossRef] [PubMed]

38. Huang, T.; Duman, J.G. Cloning and Characterization of a Thermal Hysteresis (Antifreeze) Gene with DNA-Binding Activity from Winter Bittersweet Nightshade, Solanum dulcamara. Plant. Mol. Biol. 2002, 48, 339-350. [CrossRef] [PubMed]

39. Chen, W.; Provart, N.J.; Glazebrook, J.; Katagiri, F.; Chang, H.S.; Eulgem, T.; Mauch, F.; Luan, S.; Zou, G.; Whitham, S.A.; et al. Expression Profile Matrix of Arabidopsis Transcription Factor Genes Suggests Their Putative Functions in Response to Environmental Stresses. Plant Cell 2002, 14, 559-574. [CrossRef]

40. Deslandes, L.; Olivier, J.; Theulières, F.; Hirsch, J.; Feng, D.X.; Bittner-Eddy, P.; Beynon, J.; Marco, Y. Resistance to Ralstonia Solanacearum in Arabidopsis Thaliana Is Conferred by the Recessive RRS1-R Gene, a Member of a Novel Family of Resistance Genes. Proc. Natl. Acad. Sci. USA 2002, 99, 2404-2409. [CrossRef] [PubMed]

41. Kim, K.C.; Lai, Z.; Fan, B.; Chen, Z. Arabidopsis WRKY38 and WRKY62 Transcription Factors Interact with Histone Deacetylase 19 in Basal Defense. Plant Cell 2008, 20, 2357-2371. [CrossRef]

42. Huh, S.U.; Choi, L.M.; Lee, G.J.; Kim, Y.J.; Paek, K.H. Capsicum Annuum WRKY Transcription Factor d (CaWRKYd) Regulates Hypersensitive Response and Defense Response upon Tobacco Mosaic Virus Infection. Plant. Sci. 2012, 197, 50-58. [CrossRef]

43. Zheng, Z.; Qamar, S.A.; Chen, Z.; Mengiste, T. Arabidopsis WRKY33 Transcription Factor Is Required for Resistance to Necrotrophic Fungal Pathogens. Plant J. 2006, 48, 592-605. [CrossRef] [PubMed]

44. Marchive, C.; Mzid, R.; Deluc, L.; Barrieu, F.; Pirrello, J.; Gauthier, A.; Corio-Costet, M.F.; Regad, F.; Cailleteau, B.; Hamdi, S.; et al. Isolation and Characterization of a Vitis Vinifera Transcription Factor, Vvwrky1, and Its Effect on Responses to Fungal Pathogens in Transgenic Tobacco Plants. J. Exp. Bot. 2007, 58, 1999-2010. [CrossRef]

45. Beyer, K.; Binder, A.; Boller, T.; Collinge, M. Identification of Potato Genes Induced during Colonization by Phytophthora Infestans. Mol. Plant. Pathol. 2001, 2, 125-134. [CrossRef]

46. Kalde, M.; Barth, M.; Somssich, I.E.; Lippok, B. Members of the Arabidopsis WRKY Group III Transcription Factors Are Part of Different Plant Defense Signaling Pathways. Mol. Plant. Microbe Interact. 2003, 16, 295-305. [CrossRef]

47. Wu, H.; Ni, Z.; Yao, Y.; Guo, G.; Sun, Q. Cloning and Expression Profiles of 15 Genes Encoding WRKY Transcription Factor in Wheat (Triticum aestivem L.). Prog. Nat. Sci. 2008, 18, 697-705. [CrossRef]

48. Qiu, Y.; Jing, S.; Fu, J.; Li, L.; Yu, D. Cloning and Analysis of Expression Profile of 13 WRKY Genes in Rice. Chin. Sci. Bull. 2004, 49, 2159-2168. [CrossRef]

49. Jiang, Y.; Deyholos, M.K. Comprehensive Transcriptional Profiling of NaCl-stressed Arabidopsis Roots Reveals Novel Classes of Responsive Genes. BMC Plant. Biol. 2006, 6, 1-20. [CrossRef] [PubMed]

50. Li, S.; Fu, Q.; Chen, L.; Huang, W.; Yu, D. Arabidopsis thaliana WRKY25, WRKY26, and WRKY33 Coordinate Induction of Plant Thermotolerance. Planta 2011, 233, 1237-1252. [CrossRef]

51. Singh, A.; Singh, P.K.; Sharma, A.K.; Singh, N.K.; Sonah, H.; Deshmukh, R.; Sharma, T.R. Understanding the Role of the WRKY Gene Family under Stress Conditions in Pigeonpea (Cajanus cajan, L.). Plants 2019, 8, 214. [CrossRef]

52. Song, H.; Wang, P.; Nan, Z.; Wang, X. The WRKY Transcription Factor Genes in Lotus Japonicus. Int. J. Genom. 2014, 2014,420128 [CrossRef]

53. Song, H.; Wang, P.; Lin, J.Y.; Zhao, C.; Bi, Y.; Wang, X. Genome-Wide Identification and Characterization of WRKY Gene Family in Peanut. Front. Plant. Sci. 2016, 7, 534. [CrossRef] [PubMed]

54. Yang, Y.; Chi, Y.; Wang, Z.; Zhou, Y.; Fan, B.; Chen, Z. Functional Analysis of Structurally Related Soybean GmWRKY58 and GmWRKY76 in Plant Growth and Development. J. Exp. Bot. 2016, 67, 4727-4742. [CrossRef]

55. Yilmaz, A.; Nishiyama, M.Y.; Fuentes, B.G.; Souza, G.M.; Janies, D.; Gray, J.; Grotewold, E. GRASSIUS: A Platform for Comparative Regulatory Genomics Across the Grasses. Plant Physiol. 2009, 149, 171-180. [CrossRef]

56. Sakai, H.; Lee, S.S.; Tanaka, T.; Numa, H.; Kim, J.; Kawahara, Y.; Wakimoto, H.; Yang, C.C.; Iwamoto, M.; Abe, T.; et al. Rice Annotation Project Database (RAP-DB): An Integrative and Interactive Database for Rice Genomics. Plant. Cell Physiol. 2013, 54, e6. [CrossRef]

57. Sato, Y.; Takehisa, H.; Kamatsuki, K.; Minami, H.; Namiki, N.; Ikawa, H.; Ohyanagi, H. RiceXPro Version 3.0: Expanding the Informatics Resource for Rice Transcriptome. Nucleic Acids Res. 2013, 41, D1206-D1213. [CrossRef]

58. Gasteiger, E.; Hoogland, C.; Gattiker, A.; Wilkins, M.R.; Appel, R.D.; Bairoch, A. Gene Identification and Analysis Tools on the ExPASy Server. In The Proteomics Protocols Handbook; Humana Press: Totowa, NJ, USA, 2005; pp. 571-607.

59. Kumar, S.; Stecher, G.; Tamura, K. MEGA7: Molecular Evolutionary Genetics Analysis Version 7.0 for Bigger Datasets. Mol. Biol. Evol. 2016, 33, 1870-1874. [CrossRef]

60. Hu, B.; Jin, J.; Guo, A.Y.; Zhang, H.; Luo, J.; Gao, G. GSDS 2.0: An Upgraded Gene Feature Visualization Server. Bioinformatics 2015, 31, 1296-1297. [CrossRef] 
61. Szklarczyk, D.; Morris, J.H.; Cook, H.; Kuhn, M.; Wyder, S.; Simonovic, M.; Santos, A.; Doncheva, N.T.; Roth, A.; Bork, P.; et al. The STRING Database in 2017: Quality-Controlled Gene-Gene Association Networks, Made Broadly Accessible. Nucleic Acids Res. 2016, gkw937. [CrossRef]

62. Krzywinski, M.; Schein, J.; Birol, I.; Connors, J.; Gascoyne, R.; Horsman, D.; Jones, S.J.; Marra, M.A. Circos: An Information Aesthetic for Comparative Genomics. Genome Res. 2009, 19, 1639-1645. [CrossRef]

63. Song, Y.; Chen, L.; Zhang, L.; Yu, D. Overexpression of OsWRKY72 Gene Interferes in the Abscisic Acid Signal and Auxin Transport Pathway of Arabidopsis. J. Biosci. 2010, 35, 459-471. [CrossRef]

64. Zhou, X.; Jiang, Y.; Yu, D. WRKY22 Transcription Factor Mediates Dark-Induced Leaf Senescence in Arabidopsis. Mol. Cells. 2011, 31, 303-313. [CrossRef]

65. Bakshi, M.; Oelmüller, R. WRKY Transcription Factors: Jack of Many Trades in Plants. Plant. Signal Behav. 2014, 9, e27700. [CrossRef]

66. Chen, H.; Lai, Z.; Shi, J.; Xiao, Y.; Chen, Z.; Xu, X. Roles of Arabidopsis WRKY18, WRKY40 and WRKY60 Transcription Factors in Plant Responses to Abscisic Acid and Abiotic Stress. BMC Plant Biol. 2010, 10, 281. [CrossRef]

67. Zou, C.; Jiang, W.; Yu, D. Male Gametophyte-Specific WRKY34 Transcription Factor Mediates Cold Sensitivity of Mature Pollen in Arabidopsis. J. Exp. Bot. 2010, 61, 3901-3914. [CrossRef] [PubMed]

68. Chen, Y.F.; Li, L.Q.; Xu, Q.; Kong, Y.H.; Wang, H.; Wu, W.H. The WRKY6 Transcription Factor Modulates PHOSPHATE1 Expression in Response to Low Pi Stress in Arabidopsis. Plant Cell 2009, 21, 3554-3566. [CrossRef]

69. Jiang, Y.; Deyholos, M.K. Functional Characterization of Arabidopsis NaCl-inducible WRKY25 and WRKY33 Transcription Factors in Abiotic Stresses. Plant. Mol. Biol. 2009, 69, 91-105. [CrossRef] [PubMed]

70. Shang, Y.; Yan, L.; Liu, Z.Q.; Cao, Z.; Mei, C.; Xin, Q.; Wu, F.Q.; Wang, X.F.; Du, S.Y.; Jiang, T.; et al. The Mg-chelatase H Subunit of Arabidopsis Antagonizes a Group of WRKY Transcription Repressors to Relieve ABA-Responsive Genes of Inhibition. Plant Cell 2010, 22, 1909-1935. [CrossRef]

71. Berri, S.; Abbruscato, P.; Faivre-Rampant, O.; Brasileiro, A.C.; Fumasoni, I.; Satoh, K.; Kikuchi, S.; Mizzi, L.; Morandini, P.; Pè, M.E.; et al. Characterization of WRKY Co-Regulatory Networks in Rice and Arabidopsis. BMC Plant. Biol. 2009, 9, 120. [CrossRef]

72. Ramamoorthy, R.; Jiang, S.Y.; Kumar, N.; Venkatesh, P.N.; Ramachandran, S.A. Comprehensive Transcriptional Profiling of the WRKY Gene Family in Rice Under Various Abiotic and Phytohormone Treatments. Plant. Cell Physiol. 2008, 49, 865-879. [CrossRef] [PubMed]

73. Qiu, D.; Xiao, J.; Xie, W.; Liu, H.; Li, X.; Xiong, L.; Wang, S. Rice Gene Network Inferred from Expression Profiling of Plants Overexpressing Oswrky13, a Positive Regulator of Disease Resistance. Mol. Plant. 2008, 1, 538-551.

74. Wu, X.; Shiroto, Y.; Kishitani, S.; Ito, Y.; Toriyama, K. Enhanced Heat and Drought Tolerance in Transgenic Rice Seedlings Overexpressing Oswrky11 under the Control of HSP101 Promoter. Plant. Cell Rep. 2009, 28, 21-30. [CrossRef]

75. Song, X.J.; Matsuoka, M. Bar the Windows: An Optimized Strategy to Survive Drought and Salt Adversities. Genes Dev. 2009, 23, 1709-1713. [CrossRef]

76. Rushton, P.J.; Somssich, I.E.; Ringler, P.; Shen, Q.J. WRKY Transcription Factors. Trends Plant. Sci. 2010, 15, 247-258. [CrossRef] [PubMed]

77. Muthuramalingam, P.; Krishnan, S.R.; Pothiraj, R.; Ramesh, M. Global Transcriptome Analysis of Combined Abiotic Stress Signaling Genes Unravels Key Players in Oryza sativa L.: An in Silico Approach. Front. Plant. Sci. 2017, 8, 759. [CrossRef]

78. Ning, P.; Liu, C.; Kang, J.; Lv, J. Genome-Wide Analysis of WRKY Transcription Factors in Wheat (Triticum aestivum L.) and Differential Expression under Water Deficit Condition. PeerJ. 2017, 5, e3232. [CrossRef]

79. Imran, Q.M.; Hussain, A.; Mun, B.G.; Lee, S.U.; Asaf, S.; Ali, M.A.; Lee, I.J.; Yun, B.W. Transcriptome Wide Identification and Characterization of NO-Responsive WRKY Transcription Factors in Arabidopsis thaliana L. Environ. Exp. Bot. 2018, 148, 128-143. [CrossRef]

80. Fathi, A.; Tari, D.B. Effect of Drought Stress and Its Mechanism in Plants. Int. J. Life Sci. 2016, 10, 1-6. [CrossRef]

81. Lee, H.; Cha, J.; Choi, C.; Choi, N.; Ji, H.S.; Park, S.R.; Lee, S.; Hwang, D.J. Rice WRKY11 Plays a Role in Pathogen Defense and Drought Tolerance. Rice 2018, 11, 1-12. [CrossRef]

82. Dai, X.; Wang, Y.; Zhang, W.H. OsWRKY74, a WRKY Transcription Factor, Modulates Tolerance to Phosphate Starvation in Rice. J. Exp. Bot. 2016, 67, 947-960. [CrossRef]

83. Jiang, Y.; Liang, G.; Yu, D. Activated Expression of WRKY57 Confers Drought Tolerance in Arabidopsis. Mol. Plant. 2012, 5, 1375-1388. [CrossRef] [PubMed]

84. Ren, X.; Chen, Z.; Liu, Y.; Zhang, H.; Zhang, M.; Liu, Q.; Hong, X.; Zhu, J.K.; Gong, Z. ABO3, a WRKY Transcription Factor, Mediates Plant Responses to Abscisic Acid and Drought Tolerance in Arabidopsis. Plant J. 2010, 63, 417-429. [CrossRef] [PubMed]

85. Gupta, S.; Mishra, V.K.; Kumari, S.; Chand, R.; Varadwaj, P.K. Deciphering Genome-Wide WRKY Gene Family of Triticum aestivum L. and Their Functional Role in Response to Abiotic Stress. Genes Genom. 2019, 41, 79-94. [CrossRef] [PubMed] 